\title{
Impact Of Road Geometry \&Traffic Condition on PCU Values Using PARAMICS
}

\author{
[Sandeep K Prusty ${ }^{1}$, Roopak Phadnis ${ }^{2}$, Kunal $^{3}$ ]
}

\begin{abstract}
Traffic condition in India is highly heterogeneous condition, where vehicles of varying static and dynamic characteristics occupy the same space. Expressing traffic capacity in terms of number of vehicles passing a given section of road or traffic lane per unit time will be inappropriate under these conditions. The problem of measuring traffic volume and traffic capacity of such heterogeneous traffic can be worked out by converting the different types of vehicles into equivalent passenger cars and expressing the capacity in terms of Passenger Car Unit (PCU) per hour. The objectives of this study are to develop capacity guidelines for the traffic flow on $\mathrm{NH}-17$ and to evaluate the effect of carriageway width and traffic composition on the PCU value of all the categories of vehicles. PARAMICS micro simulation software is used in this study. The PCU values of different categories of vehicles estimated from the study under heterogeneous traffic condition for observed roadway conditions and traffic compositions vary significantly with change in traffic volume. The study of effect of variation in road width under heterogeneous traffic condition on PCU indicates that for any category of vehicle, $P C U$ value increases with the increase in road width. The results of the simulation experiment conducted to study the effect of traffic composition on PCU value reveals that at a given volume level, the PCU value for any category of vehicle under heterogeneous traffic condition decreases when their proportion in the traffic stream increases.
\end{abstract}

Keywords - Carriageway Width, PCU, Microscopic Traffic Simulation, Calibration, Validation, PARAMICS

\section{Introduction}

Road transport service plays a vital role in the country's development and it's a measure of country's growth. Road transport is believed to be one of the most cost effective and preferred mode of transport for both freight as well as passengers according to MORTH [1].

${ }^{1}$ Sandeep K Prusty,

National Institute of Technology Karnataka,

India

${ }^{2}$ Roopak Phadnis

National Institute of Technology Karnataka, India

${ }^{3}$ Kunal

National Institute of Technology Karnataka, India
The transportation service in India, like other developing countries is characterized by limited road infrastructure and lack of operation and management experience. The critical issue in highway planning and management is to determine the traffic capacity of any inter - city highway or expressway as per Chandra [2].

In the last decade from 2001 - 2011, the total number of motor vehicles registered in India has increased from 5.50 crore vehicles to 14.19 crore vehicles (Statistical Year Book, India 2013). The annual increase in the number of registered motor vehicles in this decade is nearly $10 \%$ but the improvement in the road infrastructure is not that much substantial. This result into congestion on the roads, in fact many roads are reaching at their capacity. Now a day, to overcome this problem NHAI is widening the national highways from single lane to double lane and double lane to four - lane. Road widening is not the only solution for this problem, this can also solved by proper traffic planning, which results into reduction in congestion.

The proposed study aims at analysing the speed and volume characteristics of heterogeneous traffic flow to identify appropriate speed volume relationship for various traffic volume count observed on the field. As mentioned earlier, numbers of vehicles are increasing at a rapid rate but the improvement in road infrastructure is not at the same pace, which results into congestion. The analysis work in this study is carried out with the help of PARAMICS simulation software. PARAMICS is microscopic simulation software used to study the vehicular interaction at varying conditions. PARAMICS is used to study the vehicular interactions, at micro - level, over a wide range of traffic flow conditions.

\section{Study Stretch}

The study stretch selected for this study is National Highway NH - 17 near Mangalore city in southern part of India. The location selected for data collection is $10.2 \mathrm{~km}$ from Mangalore city on national highway towards Surathkal city. This location is free from any kind of obstruction and traffic flow at this location is continuous. The selected road stretch is of level terrain and straight without any direct access from the adjoining areas. The selected road for the study had a good pavement condition. This site is not close to any recreational area and also free from influence of intersection. The study stretch is four lane divided carriageway with a central median of $1.2 \mathrm{~m}$ width. Since the traffic composition in both the direction of vehicular movement is different and PARAMICS facilitates only one set of traffic composition, so two stretches are considered in this study. Stretch - 1 belongs to first stretch in which vehicular movement is towards Surathkal city and 
Proc. of the Intl. Conf. on Advances in Civil, Structural and Mechanical Engineering - ACSM 2015.

Copyright (C) Institute of Research Engineers and Doctors, USA .All rights reserved.

ISBN: 978-1-63248-039-2 doi: 10.15224/ 978-1-63248-039-2-86

Stretch - 2 belongs to second stretch in which vehicular movement is towards Mangalore city. Width of main carriageway of Stretch -1 is $7.1 \mathrm{~m}$ and that of Stretch -2 is $7.2 \mathrm{~m}$. Both the stretches have paved shoulder of width $1.5 \mathrm{~m}$. Selected stretch used in this study is shown in figure 1.

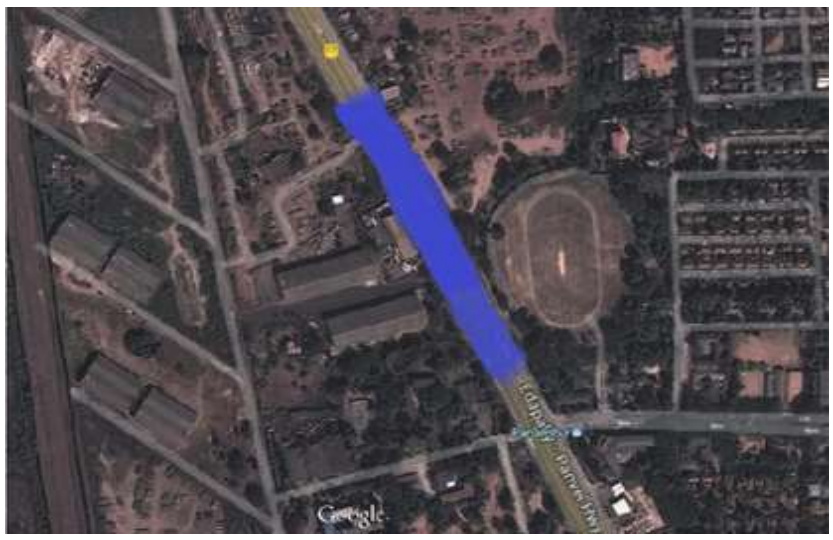

Figure 1. Study stretch for $\mathrm{NH}-17$

\section{Data Collection}

Data collection and analysis of data plays a very important role in development of simulation model. Field data should be collected with a very high accuracy because even small errors in data collection will results into an incorrect model. As per the IRC guidelines [3,] on Indian roads in general, and on Indian urban roads in particular, the traffic is highly heterogeneous, comprising vehicles of wide ranging static and dynamic characteristics as per Arasan and Arkatkar. [4].

The average time taken by each category of vehicle type to travel the trap length was measured from the recording. This time was then used to calculate the speed of vehicle along the two stretches. The observed maximum, minimum and mean speeds of various categories of vehicles and the corresponding standard deviation for Stretch -1 and Stretch-2 are shown in Table 1 and Table 2 respectively.

TABLE 1. SPEED PARAMETERS FOR STRETCH -1

\begin{tabular}{|c|c|c|c|c|}
\hline \multirow{2}{*}{ Category } & \multicolumn{4}{|c|}{ Speed Parameters (km/hr) } \\
\cline { 2 - 5 } & Max. Speed & Min. Speed & Mean Speed & $\begin{array}{c}\text { Standard } \\
\text { Deviation }\end{array}$ \\
\hline $\begin{array}{c}\text { Two- } \\
\text { Wheeler }\end{array}$ & 79 & 37 & 61 & 9.5 \\
\hline $\begin{array}{c}\text { Three - } \\
\text { Wheeler }\end{array}$ & 61 & 34 & 53 & 5.9 \\
\hline $\begin{array}{c}\text { Four - } \\
\text { Wheeler }\end{array}$ & 83 & 36 & 64 & 9.9 \\
\hline LCV & 75 & 36 & 55 & 7.9 \\
\hline HCV & 73 & 29 & 53 & 9.0 \\
\hline Bus & 83 & 31 & 62 & 13.6 \\
\hline
\end{tabular}

TABLE 2. SPEED PARAMETERS FOR STRETCH - 2

\begin{tabular}{|c|c|c|c|c|}
\hline \multirow{2}{*}{ Category } & \multicolumn{4}{|c|}{ Speed Parameters $(\mathbf{k m} / \mathbf{h r})$} \\
\cline { 2 - 5 } & Max. Speed & Min. Speed & Mean Speed & $\begin{array}{c}\text { Standard } \\
\text { Deviation }\end{array}$ \\
\hline $\begin{array}{c}\text { Two- } \\
\text { Wheeler }\end{array}$ & 80 & 39 & 60 & 6.9 \\
\hline $\begin{array}{c}\text { Three } \\
\text { Wheeler }\end{array}$ & 60 & 35 & 51 & 5.3 \\
\hline $\begin{array}{c}\text { Four }- \\
\text { Wheeler }\end{array}$ & 88 & 27 & 67 & 11.1 \\
\hline LCV & 71 & 31 & 57 & 9.1 \\
\hline HCV & 71 & 26 & 51 & 7.5 \\
\hline Bus & 81 & 27 & 64 & 11.2 \\
\hline
\end{tabular}

\section{Iv. Simulation Model Development}

Simulation modelling technique is one of the well - known technique to study traffic flow and its characteristics. A simulation has the advantage to study how the model will behave under different traffic conditions. Such microscopic simulation models are able to model individual vehicles and pedestrian for a vast area and it is possible to estimate realistic speed - volume characteristics and capacity under heterogeneous traffic conditions. The most difficult and critical process in simulating any traffic flow scenario is to calibrate the simulated model to replicate the observed conditions obtained at the field with the desired accuracy. Under these conditions, the results obtained from a simulation model would be more accurate than the results obtained through analytical modelling. Also, simulation gives us the freedom to ascertain the sensitivity of any traffic flow parameters such as composition with any other parameter such as PCU.

Data is collected in the form of video is analysed and this information is used for developing simulation model in the software PARAMICS 6.9.3. Then this model is calibrated to check the accuracy of the model. Once the calibration process is over, model is validated to estimate the roadway capacity and PCU value of the vehicles.

\section{A. Development of Base Network}

A network which accurately represents the design and operational attributes of the study stretch in the simulation software is known as the 'base network'. Development of a base network that accurately depicts the physical attributes of a study site is an important stage in model development. This stage includes the development of simulation model of road network using the manually collected data. Simulation model is developed in microscopic simulation software PARAMICS.

As it is mentioned earlier that the speed of vehicles on the field is measured with the help of trap length so to replicate 
the trap length in the model a detector is created. Base model should be developed with full accuracy so as to replicate the actual field condition on the computer. A small error in model development results into incorrect simulation results.

\section{B. Defining Model Parameters}

Defining model parameters is the second stage in the model development. This stage of the model development deals with loading traffic characteristics into the base model. The first step of this stage is vehicle modelling. Vehicle modelling deals with defining the characteristics and composition of each vehicle type that is plying on the test section. PARAMICS simulation software facilitates only one value of traffic composition for each category of vehicles. In this study, traffic composition for both the direction of vehicular movement is different so two models are developed to facilitate two different values of traffic composition.

\section{Calibration of Simulation Model}

Calibration is a process of adjusting the model parameters, road network and vehicle demand to replicate the observed data to a sufficient level to satisfy the objectives of model. In this process, if the model result matches with the observed data then the model is correct otherwise adjustments are to be made in the model and again the results are matched with observed data. This process continues till network gives nearly same results as it is observed on the field. Calibration process is necessary for any simulation modelling because not a single model can be expected to be equally accurate for all the possible traffic conditions.

Calibration is a process of comparison of the model with the real condition and this is carried out with the help of tests that requires data on the system's behaviour and the corresponding data produced by the model. The simulation for both the models were run 3600 seconds and the volume count and average speed of each category of vehicle is measured using the detector to ensure accurate simulation results. As it is observed from the video that at each point of time there were only two vehicles available on the entire width of roadway so in both the models lane discipline is followed. Hence a two lane model is considered for the simulation. Thus each vehicle is free to overtake any vehicle during the simulation on this two lane stretch.

\section{Validation of Simulation Model}

Validation is the process of checking the simulation results obtained from the calibrated model with the data obtained from the field regarding traffic characteristics. The traffic characteristics which are checked under model validation are volume count and speed of each category of vehicles. The traffic volume count observed on the field is given as input to the simulation using Traffic Demand Editor function. The traffic composition calculated from 15 minute classified video is given as an input using Vehicle Type tab available in Core Network Attribute. The heterogeneous traffic simulation model is simulated for 3600 seconds. A sample simulation run is shown in the figure 2 .

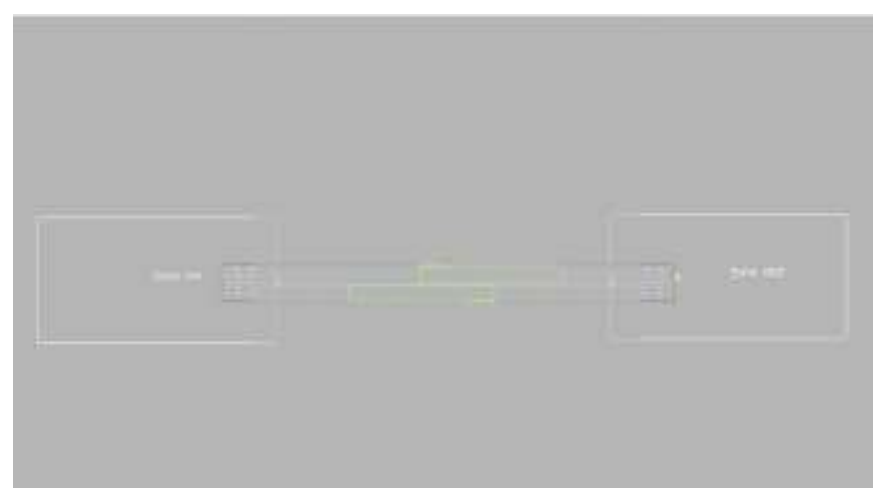

Figure 2. Design network in PARAMICS

To check the validity of the simulation model, the vehicle volume count and speed of each category of vehicles obtained from simulated model were compared with the volume count and speed of each category of vehicles observed on the field. This process is carried out for both the models.

Similarly speed of each category of the vehicle obtained from the simulation model is compared with the observed value for both the stretches. This comparison is shown in the form of histogram in figure 3 and figure 4 respectively.

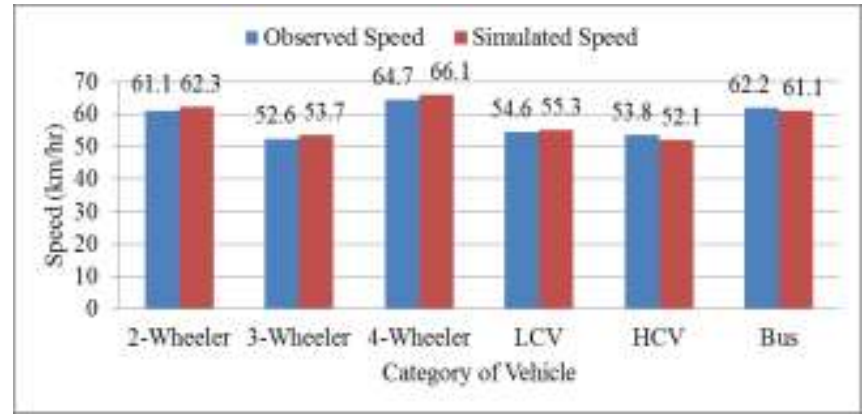

Figure 3. Comparison of observed and simulated vehicular speed conducted on Stretch -1

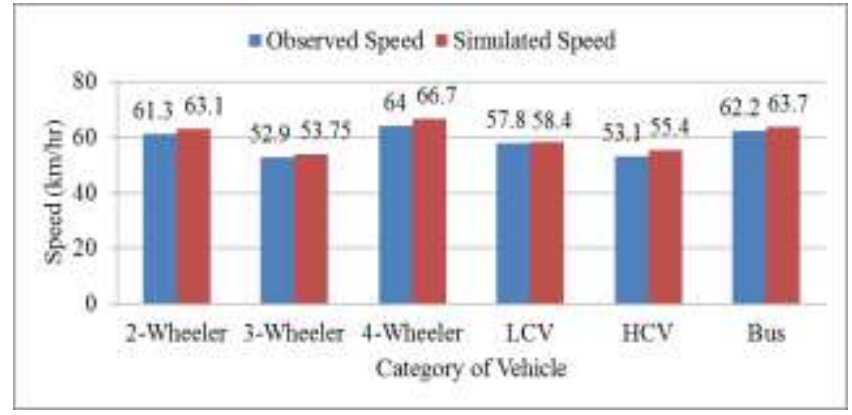

Figure 4. Comparison of observed and simulated vehicular speed conducted on Stretch -2

The validation of the model, based on the observed and simulated values of speed is also done by conducting paired $t-$ test for both the stretches. For Stretch- 1 the value of $t-$ statistics is 0.933 and for Stretch -2 the value of $t-$ statistics is 
Proc. of the Intl. Conf. on Advances in Civil, Structural and Mechanical Engineering - ACSM 2015.

Copyright $\odot$ Institute of Research Engineers and Doctors, USA .All rights reserved.

ISBN: 978-1-63248-039-2 doi: 10.15224/ 978-1-63248-039-2-86

0.581 which is less than the 2.571 , the critical value of $\mathrm{t}-$ statistics for four degree of freedom and level of significance of 0.05 .

\section{v. PCU Estimation}

The unrestricted mixing of various categories of vehicles along a road having varying static and dynamic characteristics without their physical segregation creates various complex problems for traffic engineer. One way to quantify the effect of different categories of vehicles on capacity is to convert all vehicles into an equivalent number of standard vehicles. The universally accepted vehicle is the passenger car and the factor is known as Passenger Car Unit (PCU) referred from Kadiyali [5]. The passenger car unit value of different vehicle categories do not remain constant under all the conditions, rather it depends on factors such as size and speed of the vehicle, type of road, width of road, condition of road, composition of vehicles, volume/capacity ratio etc.

In this study, the formula developed by Chandra (2004) is used to determine the dynamic PCU values of all the vehicle types available on the road space. The formula used is:

$$
P C U_{i}=\frac{V_{C} / V_{i}}{A_{C} / A_{i}}
$$

Where,

$\mathrm{PCU}_{\mathrm{i}}$ is the PCU of the subject vehicle type ' $\mathrm{i}$ '

$\mathrm{Vc}=$ Average speed of cars in the traffic stream

$\mathrm{Vi}=$ Average speed of subject vehicle type ' $i$ '

$A c=$ Projected rectangular area of a car present in traffic stream $\mathrm{Ai}=$ Projected rectangular area of the vehicle type ' $\mathrm{i}$ '.

The physical size of a vehicle is an indicator of pavement occupancy, which is important in operational characteristics of traffic stream. As we know in India, vehicles don't move in lanes due to poor lane discipline of road users as per studies made by Madhu and Velmurugan [6]. Although lanes are marked for four-wheeler but they can accommodate more than one small size vehicle easily. As the width of the vehicle is less than that of lane, the lateral gap between a vehicle and the lane marking is also used by small vehicles to move. Therefore, two vehicles can travel abreast occupying the total lane width.

To emphasize the dynamic nature of different vehicle types, Passenger Car Unit values for different categories of vehicles under heterogeneous traffic condition at eight values of volume-capacity ratio were estimated using simulation. The capacity values used for calculating volume-capacity ratio is obtained from the speed-flow relationship developed above. For the purpose of simulation, different traffic volume levels corresponding to these $\mathrm{V} / \mathrm{C}$ ratios with same composition as observed in the field for both the stretches were considered. Output obtained from simulation runs served as inputs for above equation for calculating PCU values of all the categories of vehicles at different traffic volume level. Table 3 shows the variation in value of Passenger Car Unit for Stretch- 1 as well as Stretch- 2 for eight values of volumecapacity ratios for Bus, $\mathrm{HCV}$ and LCV.

TABLE 3. PCU VALUE AT DIFFERENT V/C RATIOS FOR STRETCH- 1 \& STRETCH- 2 (BUS, HCV, LCV)

\begin{tabular}{|c|c|c|c|c|c|c|}
\hline \multirow{2}{*}{$\begin{array}{c}\text { V/C } \\
\text { ratios }\end{array}$} & \multicolumn{5}{|c|}{ Bus } & \multicolumn{2}{c|}{ HCV } & \multicolumn{2}{c|}{ CCV } \\
\cline { 2 - 7 } & $S-1$ & $S-2$ & $S-1$ & $S-2$ & $S-1$ & $S-2$ \\
\hline 0.125 & 5.20 & 5.12 & 4.56 & 4.22 & 2.32 & 2.15 \\
\hline 0.250 & 5.00 & 5.07 & 4.33 & 4.17 & 2.19 & 2.12 \\
\hline 0.375 & 4.90 & 4.96 & 4.20 & 4.04 & 2.14 & 2.06 \\
\hline 0.500 & 4.75 & 4.82 & 3.98 & 3.88 & 2.04 & 1.98 \\
\hline 0.625 & 4.64 & 4.77 & 3.77 & 3.73 & 1.93 & 1.92 \\
\hline 0.750 & 4.59 & 4.65 & 3.58 & 3.52 & 1.86 & 1.83 \\
\hline 0.875 & 4.47 & 4.57 & 3.37 & 3.38 & 1.78 & 1.79 \\
\hline 1.000 & 4.44 & 4.41 & 3.19 & 3.28 & 1.72 & 1.71 \\
\hline
\end{tabular}

\section{vi. PCU Effect Of Carriageway Width}

One of the objectives of this work is to study the effect of carriageway width on Passenger Car Unit value of different categories of vehicles, so the PCU values of the different categories of vehicles available on the road were estimated, by simulating traffic flow on different widths of road. While evaluating the effect of width of carriageway on PCU, traffic composition is kept same as that observed in the field for both the stretches. To evaluate the effect of width of carriageway on the PCU value of different categories of vehicle, the carriageway width for Stretch- 1 is changed to $12.1 \mathrm{~m}$ from $8.6 \mathrm{~m}$ and number of lanes is changed to three from two in Link tab of Editor Palette function available in modeller module. Similarly for Stretch-2, the width is changed to 12.2 $\mathrm{m}$ from $8.7 \mathrm{~m}$ and number of lanes to three from two using the same procedure as mentioned above. For both the stretches for three lane conditions, capacity is estimated in the earlier section and its values are 4210 vehicles/hour and 4320 vehicles/hour respectively. Using these capacity values, the 
Proc. of the Intl. Conf. on Advances in Civil, Structural and Mechanical Engineering - ACSM 2015.

Copyright $(\odot$ Institute of Research Engineers and Doctors, USA .All rights reserved.

ISBN: 978-1-63248-039-2 doi: 10.15224/ 978-1-63248-039-2-86

traffic volume is calculated at eight different volume-capacity as referred from Velmurugan et al [7], ratios viz. 0.125, 0.250, $0.375,0.50,0.625,0.750,0.875$ and 1.00 for Stretch- 1 as well as for Stretch - 2. Using these traffic volumes both the models was simulated. Output obtained from simulation runs of both the models served as input for the PCU equation for calculating the PCU value of different categories of vehicles at different carriageway width. Figure 5 to figure 7 shows the variation in Passenger Car Unit value of all the categories of vehicles (LCV, HCV \& Bus) at different volume-capacity ratio for carriageway width of $8.6 \mathrm{~m}$ and $12.1 \mathrm{~m}$ on Stretch- 1 . Similarly, the variation is done for remaining categories of vehicles (2-Wheeler and 3- Wheeler).

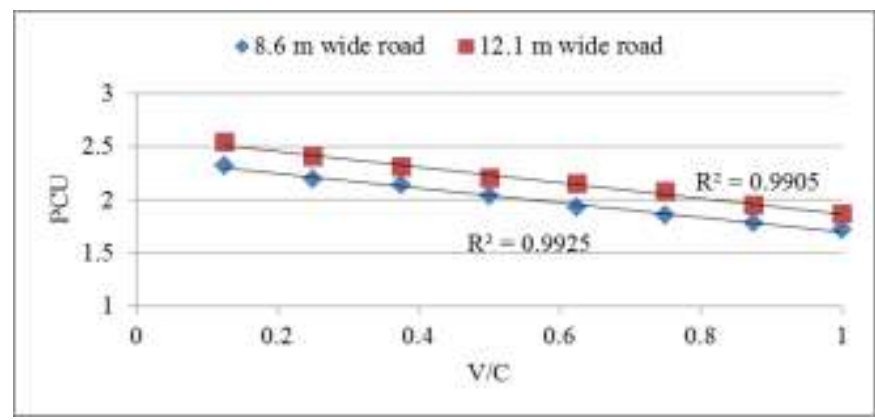

Figure 5. Variation of PCU value of LCV for $8.6 \mathrm{~m}$ and $12.1 \mathrm{~m}$ wide road

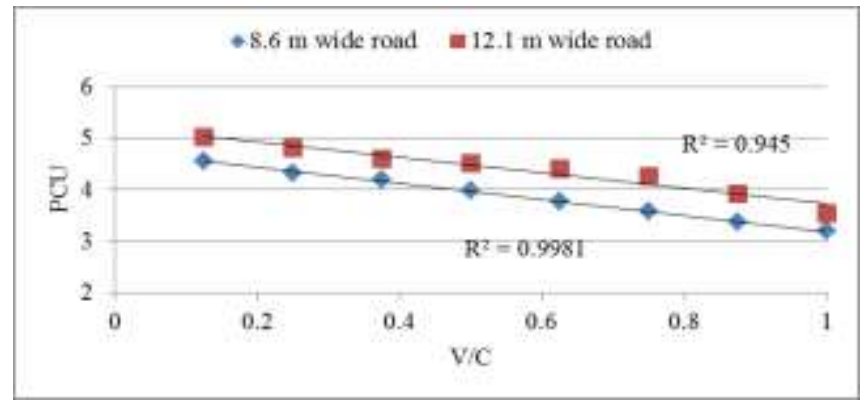

Figure 6. Variation of PCU value of $\mathrm{HCV}$ for $8.6 \mathrm{~m}$ and $12.1 \mathrm{~m}$ wide road

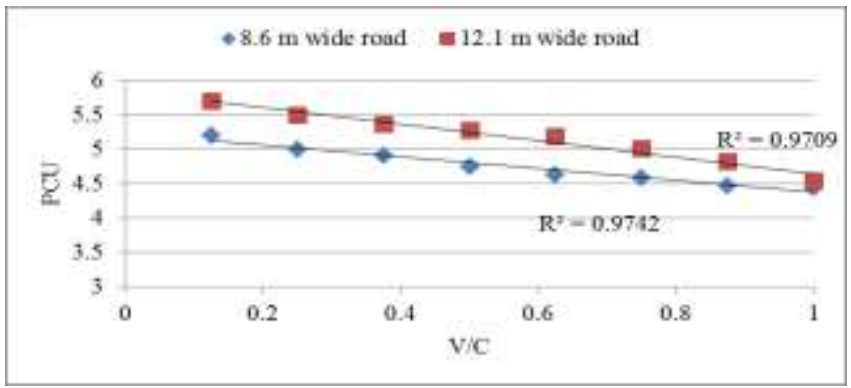

Figure 7. Variation of PCU value of Buses for $8.6 \mathrm{~m}$ and $12.1 \mathrm{~m}$ wide road
The variation in Passenger Car Unit Value for all the categories of vehicles at different volume-capacity ratio for carriageway width of $8.7 \mathrm{~m}$ and $12.2 \mathrm{~m}$ on stretch- 2 is plotted from the data obtained from the simulation run.

\section{vII. PCU Effect Due ToTraffic Composition}

It is observed in daily practice, as the composition of heavy vehicles increases the speed of the stream as well as other categories of vehicles decreases. This decreased speed when given as an input to the PCU equation results in smaller value of PCU. But in case of small vehicles, the situation changes entirely. So we can say that as the composition changes value of Passenger Car Unit for vehicles also changes. This change in value of Passenger Car Unit is proved in this study. The process carried out to study the effect of traffic composition on the PCU is in following manner. Firstly, for both the stretches, a traffic stream containing only cars and width of carriageway as observed in the field is simulated. With the help of outputs from simulation runs of both the stretches, speed - flow relationship is developed for both the stretches.

Next step is to add the proportion of bus into the traffic stream containing only cars. Four proportions of buses are selected i.e. $10 \%, 20 \%, 30 \%$ and $40 \%$ and at these proportions model is simulated. Using the simulation results speed - flow curves are developed for all the proportion of buses. Using these speed - flow relationship capacity is estimated in each case. The results of this study as shown in figure 8 show that as the composition of bus increases capacity of the road decreases. Figure 8 shows the speed-volume relationship for car and bus traffic stream for Stretch-1. Similarly figure 9 shows the speed-volume relationship for car and bus traffic stream for Stretch-2 at above mentioned proportions.

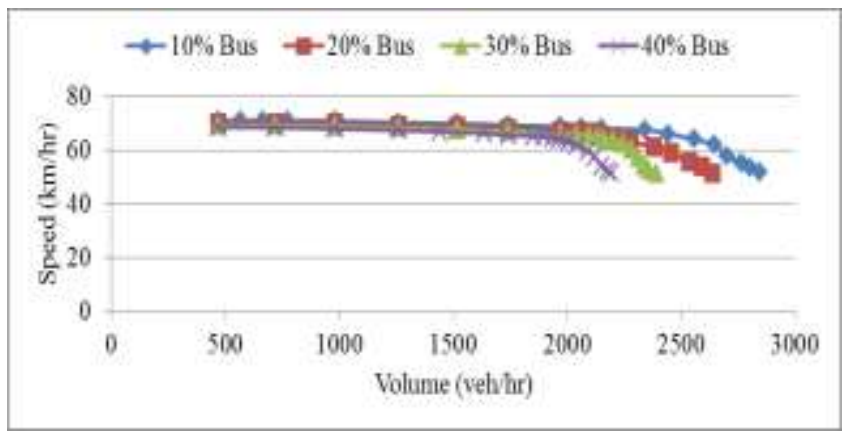

Figure 8. Speed - volume relationship for car and bus traffic stream on Stretch -1 
Proc. of the Intl. Conf. on Advances in Civil, Structural and Mechanical Engineering - ACSM 2015.

Copyright $(\odot$ Institute of Research Engineers and Doctors, USA .All rights reserved.

ISBN: 978-1-63248-039-2 doi: 10.15224/ 978-1-63248-039-2-86

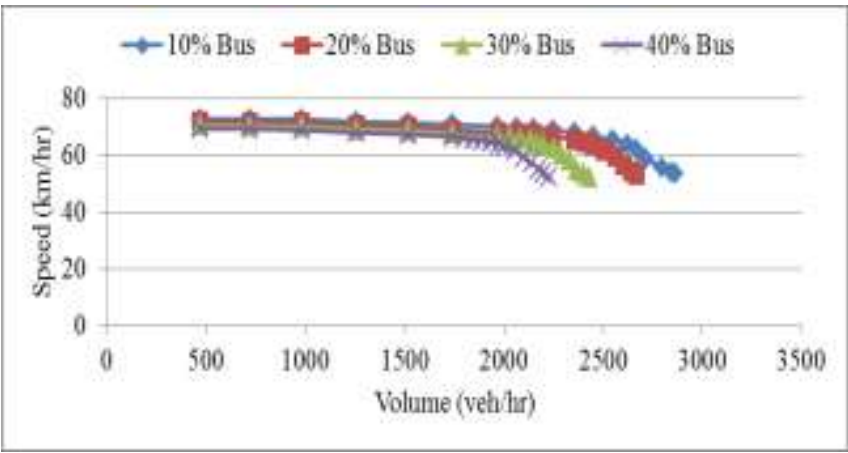

Figure 9. Speed - volume relationship for car and bus traffic stream on Stretch -2

The capacity estimated from the above speed-flow relationships for different composition of buses were used to find the volume-capacity ratio. At these volume-capacity ratios again the model is simulated for all the four proportions of buses. Using the output from the simulation run as an input to PCU equation, the PCU value of bus is calculated for all the four compositions at different V/C ratio values. The same procedure is carried for all the types of vehicles for both the stretches.

\section{vIII. Checking Accuracy Of PCU Values}

This step is carried out to check the accuracy of Passenger Car unit values of the vehicles obtained from the study. The procedure adopted for checking the PCU values of the different categories of vehicles is carried out for Stretch- 1 only. Firstly the heterogeneous traffic flow for the observed traffic composition in the field is simulated. This simulation run is carried at eight different volume-capacity ratios and the number of vehicles of each category passing through the detector was noted. Then the vehicles of different categories were converted into equivalent passenger cars by multiplying the number of vehicles with their corresponding PCU values as mentioned above. This product is then added to get the total traffic volume in terms of PCU/hr for Stretch-1. Similarly the traffic stream is simulated for cars-only traffic for the same set of volume-capacity ratios values; this will give the traffic volume in terms of number of cars for the selected set of volume-capacity ratio.

At the end the traffic volume measured in terms of PCU is compared with the traffic flow in terms of number of passenger cars for the same set of volume-capacity ratios. This comparison is shown in figure 10 .

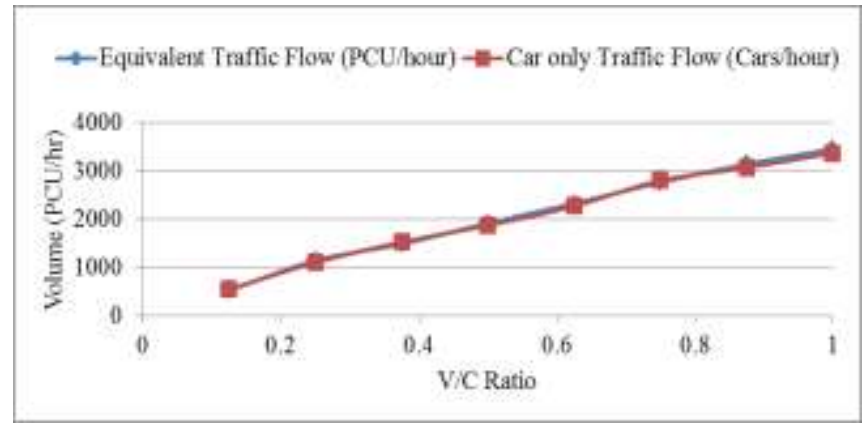

Figure 10. Comparison of heterogeneous traffic and cars-only traffic flow

It can be seen that the traffic flow in terms of PCU/hour and vehicles/hour in case of cars-only flow matches fairly well at each volume-capacity ratios value indicating the accuracy of estimated PCU values. A paired $t$-test based on the two values was also done to check the accuracy of PCU values. In this the calculated value of $t-$ statistics was 0.961 and the critical value of $t$-statistics for a level of significance of 0.05 for seven degree of freedom is 2.37 . This implies that the difference between the traffic volumes measured in the terms of PCU per hour and passenger cars per hour is fairly low and the estimated PCU values are accurate to a great extent.

\section{Ix. Conclusions}

The following are the important conclusions drawn based on this study:

- The validation results of simulation model of the heterogeneous traffic flow developed in microscopic simulation model PARAMICS indicate that the model is capable of reproducing the heterogeneous traffic flow conditions on intercity roads to a highly satisfactory extend for observed traffic flow conditions.

- The estimated capacity for observed traffic composition for one direction of movement on four - lane divided road with a carriageway width of $8.6 \mathrm{~m}$ to $8.7 \mathrm{~m}$ is ranges from $3300 \mathrm{PCU} / \mathrm{hr}$ to $3500 \mathrm{PCU} / \mathrm{hr}$. Similarly estimated capacity for six - lane divided road for one direction of movement with a carriageway width of $12.1 \mathrm{~m}$ to $12.2 \mathrm{~m}$ ranges from $5400 \mathrm{PCU} / \mathrm{hr}$ to $5700 \mathrm{PCU} / \mathrm{hr}$.

- The results of the simulation experiment conducted to study the effect of traffic composition on PCU value reveals that the PCU value for any category of vehicle under heterogeneous traffic condition decreases when their proportion in the traffic stream increases.

- The check performed to ascertain the accuracy of PCU values estimated by the simulation model the comparing 
Proc. of the Intl. Conf. on Advances in Civil, Structural and Mechanical Engineering - ACSM 2015.

Copyright $(\odot$ Institute of Research Engineers and Doctors, USA .All rights reserved.

ISBN: 978-1-63248-039-2 doi: 10.15224/ 978-1-63248-039-2-86

the flow of car only and the PCU equivalent of heterogeneous traffic on the two - lane divided road indicates that the estimated values are fairly accurate.

- The model developed in present study has the potential to be used for evaluating traffic management measures such as segregation of vehicles on major urban roads, provision of exclusive lanes for buses or bicycles, banning of certain categories of vehicles from selected stretches of roads, etc.

\section{Acknowledgement}

This work has been completely sponsored by TEQIP-II NITK, Surathkal. We acknowledge Dr. Suresha S. N. for his regular guidance and Dept. of Civil Engg. NITK for their support.

\section{References}

[1] Ministry of Road Transport and Highways (2013). Annual report, New Delhi.

[2] Chandra, S. (2004). "Effect of road roughness on capacity of twolane roads." Journal of Transportation Engineering, Vol. 130, 360-364.

[3] Indian Roads Congress (IRC) (1990). "Guidelines for capacity of urban roads in plain areas.” IRC: 106, New Delhi, India.

[4] Arasan, V. T., and Arkatkar, S. S. (2011). "Derivation of capacity standards for intercity roads carrying heterogeneous traffic using computer simulation." Procedia Social and Behavioral Sciences, 16(2011), 218-229.

[5] Kadiyali, L.R. (2006). Traffic engineering and transport planning. Khanna Publishers, New Delhi.

[6] Madhu, E., and Velmurugan, S. (2011). "Estimation of road capacity of eight-lane divided urban expressways under heterogeneous traffic through microscopic simulation models." International Journal of Science and Technology Education Research, Vol.1 (6).

[7] Velmurugan, S., Madhu, E., Ravinder, K., Sitaramanjaneyulu, K., and Gangopadhyay, S. (2010). "Critical evaluation of roadway capacity of multi - lane high speed corridors under heterogeneous traffic conditions through traditional and microscopic simulation models." Journal of the Indian Roads Congress, Vol. 71-3, 235-264.

About Author (s):

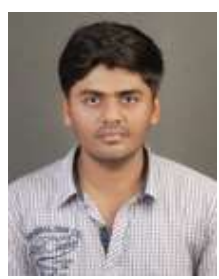

Sandeep Kumar Prusty

M. Tech (HTTA),

Transportation System Engineering,

Dept. of Civil Engg, NITK,

Surathkal, Karnataka

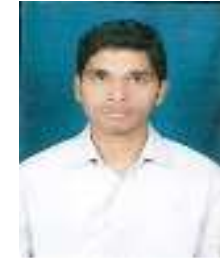

Roopak Phadnis

M.Tech,

Transportation System Engineering, Dept. of Civil Engg, NITK, Surathkal, Karnataka

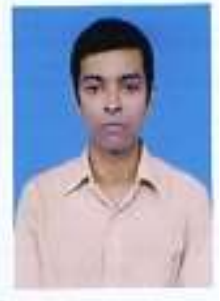

Kunal

M. Tech ,

Transportation System Engineering, Dept. of Civil Engg, NITK,

Surathkal, Karnataka 